\title{
Anthropological Forum
}

A Journal of Social Anthropology and Comparative Sociology

\section{Wild-ing the Ethnography of Conservation: Writing Nature's Value and Agency In}

\section{Laur Kiik}

To cite this article: Laur Kiik (2018) Wild-ing the Ethnography of Conservation: Writing Nature's Value and Agency In, Anthropological Forum, 28:3, 217-235, DOI: 10.1080/00664677.2018.1476222

To link to this article: https://doi.org/10.1080/00664677.2018.1476222

\section{Published online: 21 May 2018.}

Submit your article to this journal $₫$

\section{Llll Article views: 363}

Q View related articles $\asymp$

View Crossmark data $₫$ 


\title{
Wild-ing the Ethnography of Conservation: Writing Nature's Value and Agency In
}

\author{
Laur Kiik (D) ${ }^{\mathrm{a}, \mathrm{b}}$
}

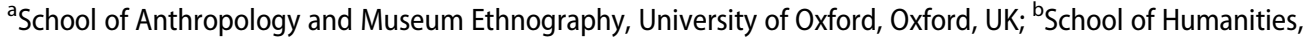
Tallinn University, Tallinn, Estonia

\begin{abstract}
When reading ethnographic literature on nature conservation, one may wonder: where has nature gone? Social anthropologists have written nuanced ethnographies of how the environmental projects of governments and transnational NGOs encounter, dispossess, clash culturally with, and try to govern native people across the world. Yet, these diverse ethnographies often say little about what motivates those encounters firstly: local and global nature, especially wildlife, plants, and the planet's ecological crisis. Thus, this paper seeks ways how ethnographic writing on conservation practice could better reflect that the planet's many self-willed, struggling, and valued non-humans, too, enter conservation's encounters. To find paths toward such a 'wild-ing' of ethnography, the paper locates and reviews disparate materials from across the social-anthropological literature on biodiversity conservation. The review is structured through three questions: How does and could the ethnography of conservation represent nature's value? How can it show that animals, plants, and other nature make and meet worlds? How can it incorporate natural science data about non-human worlds and ecological crisis? Altogether, we understand nature conservation clearer through the interdisciplinary and more-than-human ethnography of worldmaking encounters. Such wilder ethnography may also better connect people's suffering and nature's vanishing - as problems both for anthropology and conservation science.
\end{abstract}

\section{KEYWORDS}

Value of nature; non-human agency; political ecology; interdisciplinary ethnography; ethics of anthropology

\section{Introduction}

Over the last 30 years, social anthropology has helped us understand nature conservation as a practice that involves much more than biodiversity, natural science research, and technical solutions. Numerous anthropological ethnographies, particularly those with a political-ecology approach, have elucidated how conservation is a social process and a political project, inevitably imbued with dispossession, power, and cultural difference. Yet, reading these ethnographies, I am often left wondering: Where has nature gone? Whereas this rich literature reveals the varied ways in which local communities experience transnational conservation interventions, it has little to say about the life-worlds of animals, plants, or 
more-than-human landscapes that conservationists try to protect. Many ethnographies about conservation practice sideline other-than-human lives and world-makings, nature's multiple forms of agency and impact, nature's values, and indeed, the shapes, states, and modes of the local and global crisis of nature. No matter how humanly construed, living nature continues to impact and motivate human social worlds, including conservation projects. The reality of the ecological crisis is actively shaping the places under conservation management and the planet as a whole. My goal in writing this article is to seek ways how the ethnography of conservation's worldwide encounters could better reflect this.

As I ponder this gap in the ethnographic literature, I think of advances in other fields of anthropology that have attended to the lives of the many non-humans who participate daily in our humanly lived worlds. Whether by drawing from natural sciences or from the humanities, fields such as human ecology, ethnobiology, anthrozoology, multispecies ethnography, environmental humanities, and so forth, have all integrated nature into the analysis of people-environment relations. These fields have often offered insights that speak directly to the concerns of conservation. This ecological and holistic tradition within anthropology thus also inspires my paper's search for paths toward 'wild-ing' the ethnography of conservation practice.

In this paper, 'wild-ing' means filling our ethnographic textscapes with a self-willed and valuable nature - with various other-than-human life-worlds, the planetary facts of ecological crisis, and awe. The currently popular term 'rewilding' often denotes a contentious conservationist movement for massively restoring land areas into less humancultivated and more self-willed conditions, especially for bringing back long-lost top predators, other wildlife, and their ecological interactions. Conservationists also debate and advance other kinds of rewilding. For some, the concept has come to include changing not only physical ecology, but also humans - especially industrialised societies and their people's minds, hearts, lives, and culture. Namely, 'rewilding ourselves' means noticing and caring compassionately for non-human lives, allowing those life-forms' wills and interests to impact ours, sometimes in unpredictable and risky ways, and becoming enchanted with nature. This paper explores a similar kind of 'wild-ing' - writing a valuable and self-willed nature into our ethnography. Importantly, the wildness that this paper seeks is not the notion of pristine nature, but the planet's ecosystems and species as continuing to live despite all the constraints that humans put in their way.

This paper thus asks two questions: How is nature - its value, non-human life-worlds, and worldwide crisis - represented in the ethnography of conservation? How to further 'wild' our ethnography, both analytically and practically?

I wrote this paper to prepare for my doctoral ethnographic fieldwork - which is about how transnational nature conservation and an ethno-national revolution movement meet each other in war-torn Burma/Myanmar's ethnic Kachin region. The paper's exploration of writing about nature arose from my desire to take seriously both the planet's ecological crisis and the Kachin region's humanitarian and military-political crisis, and to try discussing Burma's tensions around nature conservation more fairly, accurately, and openly (Kiik 2016, 223-226). I also wrote one more paper on the ethnography of biodiversity conservation. There, I ask how to better represent conservation professionals' social worlds - the transnational culture of 'Conservationland' (Kiik 2019). 
The following discussion is structured into four sections. First, I briefly summarise the ethnographic literature on 'conservation encounters'. Although nature appears rarely in these ethnographies, this diverse literature does contain dispersed, valuable discussions, and materials. I thus map, aggregate, and evaluate these existing resources in the article's three core sections that seek paths toward further wild-ing the ethnography of conservation. Each of these three sections begins with a question. First, how to engage ethically and ethnographically with the environmentalist valuing of nature? Second, how to treat wildlife and other nature as actors that participate in conservation's encounters? Finally, how to use insights from the natural sciences toward wilding conservation ethnography?

\section{The Anthropology of Conservation Encounters}

The starting point for anthropological ethnographies about conservation practice is usually a conservation encounter. By a conservation encounter I mean the encounter between any human community, an area's living and non-living nature, and a state's or NGO's nature conservation program. Such encounters are increasingly common across the world. These encounters sometimes lead to clash, sometimes to cooperation, sometimes to an awkward gap and co-existence. Indeed, the elementary notion of 'encounter' is helpful for analysing conservation projects because it prevents assuming any specific outcome. Moreover, the term 'encounter' - cultural, ontological, and inter-species encounter - helps underline the key role played by non-human nature, which is this article's goal.

Anthropological ethnographies which investigate how native societies experience the arrival of outside-led conservation projects have bourgeoned during the last few decades (Anderson and Berglund 2003; West, Igoe, and Brockington 2006). Theoretically, this literature has drawn variously from previous legacies of environmental, political, economic, and broader sociocultural anthropology. Often, it is written within the interdisciplinary, mainly neo-Marxian field of political ecology. In my reading, these ethnographies of conservation's social effects raise three major themes: dispossession, governance, and cultural clash (Kiik 2019).

First, literature that tackles dispossession and inequity has highlighted the widespread phenomenon of 'green grabbing' - the dispossession of local communities from their lands, rights, and resources in the name of nature conservation, especially for protected areas (Anderson and Berglund 2003; West, Igoe, and Brockington 2006; Brockington, Duffy, and Igoe 2008; Fairhead, Leach, and Scoones 2012). Instead of blaming local populations for environmental degradation, such research also keeps reminding conservationists about the larger structural inequity in the global political economy: wealthy consumer societies and the rich upper classes have, grab, and use many more resources than the developing countries' farmers, labourers, or hunter-gatherers.

Second, the literature on governance and power has viewed conservation as a particular governmental vision and plan for how humans and nature should be. This literature has shown how nature conservation tries to regulate local societies and make them manageable (for example, Bryant 2002; Agrawal 2005). Indeed, conservation may help a given state's elites broaden their power, not least by dominating resistant populations by military violence (Peluso 1993). Conservation also tries transforming people's internal mental worlds - to make people feel inherently responsible for protecting the environment and have them thus behave accordingly. 
Third, the ethnographies have investigated inter-cultural conflict in conservation encounters, especially when conservationists and native people clash due to their cosmological disagreements about what nature and reality are. Anthropologists have shown how transnational conservationists bring with them modernist or 'naturalist' assumptions, worldviews, and knowledge practices which do not fit into foreign, especially animist, social worlds (for example, Novellino 2003; West 2006; Nustad 2015). The ethnographies often juxtapose conservationist ideas against how various animist peoples 'regulate' ritually their local animal populations, treat some animals as persons, and maintain kinship-like relations with certain species and landscapes. Authors have also highlighted the complexity in translating such modern concepts as 'nature', 'environment', 'conservation', and 'environmentalism' across the world's cultures (for example, Campbell 2013, 2009).

These three themes are, of course, not exhaustive. Moreover, they overlap in much of the literature. Yet, these themes do show a reason why social anthropologists have found conservation encounters interesting. Namely, when professionals from the West or from cities intervene in indigenous and rural societies across the world, conservation becomes an encounter between some of the most disparate parts of humankind. The following discussion builds on anthropology's rich literature on conservation encounters by asking: how can ethnography help us notice that the planet's many self-willed, struggling, and valued non-humans, too, enter these encounters?

As I pursue such wilder ethnography, I am encouraged by the increasingly busy interface between conservation science and environmental anthropology. As mentioned, anthropology's engagements with non-human nature and its conservation are long and many - from primatology to ethnobotany, from human ecology to political ecology, from zooarchaeology to ethnographies of animist ecology, and more. Conservation scientists and practitioners have engaged with the more ecological and the applied parts of anthropology for decades. Nature conservation, in general, is involving ever more social science disciplines, most formally in the international Society for Conservation Biology's growing Social Science Working Group. Many conservation scientists and practitioners have engaged pragmatically with economics and other social sciences which offer them somewhat familiar 'language' - quantitative data, technocratic solutions, and a relatively objectivist outlook. Thus, environmental anthropologists Brosius and Hitchner (2010) regret that conservationists prioritise those disciplines which 'valorise clarity over complexity' and which hence offer scaled-up, de-contextualised, and transportable models for theory and practice. Indeed, conservation scientists have found it hard to reconcile their epistemologies with the 'complicated and messy' stories of anthropological ethnography. Sometimes, conservation scholars can neglect engaging social-anthropological literature because the transnational culture of academic publishing empowers and values natural science over qualitative social science. Social anthropologists, similarly, do not much engage with conservation-biology literature, as this paper notes below. However, some conservationists are now increasingly drawing insights from more qualitative, humanistic, and critical fields, such as mainstream sociocultural anthropology (Redford 2011). The proposal that the current geological era be understood as the Anthropocene because (rich) humans have become the Earth's key geological agent - too, has sparked conversations that lay ground for more collaboration between biodiversity conservation and the ethnographic study of humanity. 


\section{Representing Nature's Values}

How should social anthropologists represent the worldwide destruction of animal lives and other nature? Two scholars clashed over this question recently on the pages of Anthropological Forum.

Namely, in a 2016 journal special forum, Kopnina (2016) bemoans that those anthropologists who criticise nature conservation for causing social injustice are ignoring the suffering of animals and other 'ecological injustice'. Kopnina is a social anthropologist who comes from a 'deep ecology' perspective and maintains that 'humans and non-humans should be treated equally'. Her paper is characterised by a rhetorical tactic whereby terms from human rights advocacy and social criticism are turned back against the social critics of conservation. For example, the paper talks of 'genocide', 'mass slaughter', 'colonial practices', 'blatant discrimination', and so forth, but as committed against the world's animals and species. It thus likens environmental anthropologists to apologists for genocide, moreover warning about the 'legal repercussions of ecocide'. The paper regrets that in the 'after nature' 'vacuum' created by anti-realist, social-constructivist scholarship, 'nobody can hear an animal scream or a tree fall'.

In an invited comment to Kopnina's paper, the environmental anthropologist Paige West (2016a) defends the discipline's integrity. West's comment dismisses Kopnina's paper as 'a selective misreading of the literature' that sets up 'a poorly constructed "straw man"' and fails to engage the richness and nuance of actual ethnographies of conservation. It also condemns the paper for 'a deeply problematic section accusing scholars who attempt to understand the complexities of the social impacts of conservation of "political correctness"'. West's comment thus does not directly engage Kopnina's accusation of apologism for animal 'genocide'. It does not aim to show how anthropologists defend the value or rights of animals and other nature. Instead, the comment lays out an alternative program - one where anthropologists auto-critique any assumptions we bring from 'late liberalism', decolonise our research practices, engage with indigenous scholarship, publish in more accessible venues, and encourage clear, easily readable writing. Kopnina's followup reply misunderstands this wide-reaching program by miscalling it an 'extended reflection of open access publication'.

These two scholars thus spoke past each other in a way that is illuminating. They identified no common ground between their disparate agendas. Kopnina has in recent years published numerous similarly militant and rhetoric-heavy, mostly non-empirical writings - without gaining much attention in mainstream environmental anthropology which is better represented by West. Yet, Kopnina's heterodox writings are like a jester in the king's court they shine light onto an unspoken, widespread reality in the ethnography of conservation.

Namely, in many anthropological ethnographies of conservation practice, there seems little space for valuing nature - the plants, animals, this planet's non-human worlds - in and of itself. This reflects social anthropology's traditionally human-centred ethics, evidenced in the conservation ethnographies' topical foci and occasional political proposals. As I begin discussing this literature, I seek paths toward a more explicitly pro-conservation anthropology, as demanded by Kopnina, but try finding those paths first in the rich literature of conservation ethnographies, as acclaimed by West.

As summarised above, the ethnographies have mainly documented how conservationists intervene within human society. Indeed, it is expectable that anthropologists - people 
who study humankind - are primarily concerned with people, their thoughts, and their lives. A significant portion of the ethnographies has thus studied how conservationand-development projects have impacted local society, especially how conservationists have misread and maltreated already deprived people. This focus exemplifies how cultural anthropology, especially in North America, has in the last few decades paradigmatically highlighted social injustice and people's suffering (Robbins 2013; Ortner 2016). Continuing these ethnographic criticisms against conservation is vital, especially when conservation involves authoritarian, exploitative, or reckless practices.

Yet, when we are writing ethnography about nature conservation, should we not engage also with the nature that motivates and participates in conservation's worldwide encounters? The human ideas and practices known as 'conservation' emerge from and within the planetary realities of degraded and disappearing landscapes, plants, and animals, and global ecological crisis. Simultaneously, they emerge from and within the remarkable abundance, diversity, and beauty of life across the planet.

Many ethnographies of conservation encounter, as outlined above, do not explicitly treat ecological crises as worthy problems or concerns in and of themselves. They do not explicitly voice concern about the future of the fieldsite's endangered animals or ecosystems, for example. They often show little sympathy for conservation as a goal or a kind of world-making on its own terms. The ethnographies are, usually, highly sceptical of conservation professionals who, moreover, rarely receive focused attention (Kiik 2019). While authors do sometimes mention that they support conserving nature, their writing does not include extended discussions or arguments that are openly driven by this commitment. The expressed commitment is to human welfare, justice, and rights. The main register is criticism against conservationists, not concern for nature.

The very existence of living worlds beyond human perception and impact may get denied or sidelined. This can happen especially when ethnographers aim to debunk inaccurate and romantic notions of 'wilderness' - including by showing how humans have historically shaped supposedly 'wild' landscapes into 'anthropogenic nature' (for example, Fairhead and Leach 1996; Anderson and Berglund 2003; Raffles 2014). Alternatively, an animal species may function as a 'tool' for ethnography to study human society and oppression (for example, Jalais 2014).

Thus, in much ethnography of conservation encounters, an animal or plant population's or ecosystem's actual situation as a question remains wholly unaddressed - suggesting as if a place's nature itself were irrelevant. Some ethnographies foreclose discussing unsustainable hunting or gathering by affirming that Animist people do not have a concept of species extinction and may, thus, find conservationists' warnings about life-forms going extinct cosmologically absurd. Understandably, physical ecology is not the main focus in ethnographic research. Yet, it could deserve at least some consideration - if for no other reason, then, because nature is a part of those encounters and its realities impact those, otherwise all-human encounters.

The ethnographies' political proposals, too, rarely consider 'nature' as a value in itself. For example, Haenn (2005) envisions a 'sustaining conservation' where a social justice perspective is integral - without mentioning any role for nature as an inherent value. Nustad's (2015) analytical proposal to treat conservation conflicts by assuming the existence of multiple realities, too, mentions no value of nature. So too does Blaser's (2016) proposal for an 'ontological politics' that would rely on indigenous customs when creating 
conservation policy for caribou. Even when Lowe (2006, 155-156) advises to 'organize conservation around [an indigenous] peoples' natures ... rather than scientists' biodiversity', she is prioritising people's desires - namely, this indigenous group's and the scientists' 'mutual desires... for species abundance and diversity'. Lowe thus excludes nature's intrinsic value - about which the scientists' ideological term 'biodiversity' tries to communicate.

That said, several ethnographies do declare support for the work of conserving nature, while lamenting some social anthropology's seeming lack of concern. For example, again, Lowe $(2006, \mathrm{x})$ pursues a social anthropology that appreciates nature's value and loss:

[A] consequence of the mid-1990s political economy approach to anthropology was that it was easy to lose sight of 'nature' and the fact of documented losses in the abundance and variety of life forms on earth. While biologists have often been misguided in their methods for convincing the rest of us of the value of biodiverse nature, this says nothing of the existence (or disappearance) of plants and animals themselves ...

Another issue for [my book], then, is how to maintain an antifoundationalist perspective on nature while simultaneously remaining attentive to the stories of nature [that] biologists wish to tell. It would make no sense, after all, to be in favor of less biological diversity. Nor does it make sense to see biologists and conservationists as the most harmful actors in scenarios of social abjection or schemes to remake nature in one's own image.

Indeed, attending to the biologists' stories is a key way how some ethnographers have considered nature's value in their writing. Some ethnographies have explored how conservationists feel, debate, and strategise about nature's value - intrinsic, practical, aesthetic, sacred, or other value (Milton 2002; Toussaint 2005). When ethnographies discuss conservationists' love toward nature, they advance more broadly the anthropology of professionals in nature conservation (Kiik 2019). Beyond the culture of conservationists, though, our ethnographies could communicate independently a valuing of and caring about the crisis of nature - and our fieldsites' many non-human life-worlds.

Expressing sympathy for conservation-work, Brosius and Hitchner $(2010,154)$ challenge those fellow social anthropologists who have condemned conservation NGOs' recent bioregional and financial strategies. Perhaps the end-goal of valuing and keeping nature justifies the means. They ask:

Given the low value conventionally afforded to biodiversity ..., is it not a good idea to use the master's tools to preserve it? Is it not better that maps, financial instruments and other such embodiments of power be directed towards the protection of biodiversity rather than to enriching the shareholders and CEOs of extractive industries? In a world increasingly characterised by corporate hegemony, don't we want organisations like WWF and TNC to be more powerful? Conservation is expensive and becoming more so all the time. We should not expect conservation organisations to be effective if they cannot compete in domains where power and influence are unapologetically exercised as a matter of course.

While many other social anthropologists may disagree with such pragmatic approaches to conservation, many do also likely care for - and engage in - conserving nature much more than their critique-oriented writings reveal. Most explicitly, Theodossopoulos (2003) and Haenn (2005) discuss how they originally came to their ethnographic research projects as environmentalists who had been disillusioned; and in a footnote, Cepek $(2012,227)$ writes: 'I wish to state that I consider myself to be a conservationist'. West (2016b) and colleagues 
have for years run an NGO that trains Papua New Guinean biology students, helping them apply to study abroad, return to work in conservation, and affirm their country's 'full sovereignty'.

However, when further seeking common ground between the values of social anthropology and biodiversity conservation, we may approach ethical challenges. For example, pondering the above clash between the two anthropologists, Kopnina and West, I speculate that both deep ecology's and social justice's advocates value both human lives, animal lives, diverse species, and other nature, but also believe - implicitly - that different lifeforms have relatively more or less value. To address the relationship between social anthropology and nature conservation then, perhaps we could engage the controversial philosophical challenge of articulating how we actually think that different species' and animals' value may be hierarchised (Kagan 2016)?

Indeed, Heatherington (2010) proposes that seeking ethical discomforts should itself be environmental anthropology's paradoxical task. Heatherington writes how people at her fieldsite confronted her over whose side she stands on: do you support our right to cut wood in the Commons or do you support the new conservation Park? One native person challenged her: 'You cannot be an anthropologist and an environmentalist at the same time!' This claim led Heatherington to reflect:

[B]oth anthropology and environmentalism imply ethical orientations of advocacy ... In a field historically engaged with encounters between groups of unequal power, we [anthropologists] strive to transcend structural complicity and bear witness to poverty, distress, suffering, creativity, integrity, humanity, and hope ... An environmental scholar, meanwhile, must bear witness for those entirely without human language, at a time of undeniable and growing urgency. To advocate on behalf of non-human species and their homelands, to speak on behalf of skies and winds and tides, demands a very distinctive form of attentiveness and understanding. So it is a paradox of environmental anthropology that we must be tuned simultaneously into different registers, spoken and silent ..., so that we continually discover discomforts and contradictions. (4-5)

Thus, the ethical hierarchies, anxieties, and choices which both many environmental anthropologists and nature conservationists tackle daily could themselves be viewed as ethnography's and conservation's common ground. The greater the human suffering, poverty, and tragedy that we witness, the more can us focusing on nature and wildlife feel wrong. Because the society that I research suffers from war and deep injustice, I often feel that studying conservation practice here can be absurd and obscene. Perhaps, such ethical anxieties are themselves a worthwhile and necessary object of anthropological meditation. Such feelings call for heightening our senses toward holding in sight, constantly, both the worldwide destruction of nature and the destruction of people's lives.

One helpful approach to sensing the loss of wildlife has been championed by a collective of environmental humanities scholars under the title 'extinction studies'. These authors have meditated on how we, as people, should relate emotionally and ethically to global wildlife's rapid loss and the demise of the planet's ecosystems (Rose 2011; Rose and Van Dooren 2011; Dooren 2014; Kirksey 2014; Haraway 2016; Heise 2016; Rose, van Dooren, and Chrulew 2017; see also Sodikoff 2012). The authors cultivate compassion and community with other-than-human life-forms - caring both about their individual suffering and their populations' extinction. Beyond conserving and hoping, they emphasise mourning the disappearing animals and natural worlds. From an ethnographic 
viewpoint, this literature is perhaps more prescriptive rather than descriptive. But perhaps such prescription can help - as one path toward wilding the ethnography of conservation.

Finally, ethnography could help value and care for the lives and deaths of other-thanhuman beings better, if it treated them as ethnographic characters - as real-life, unique, acting, working characters who, too, make our shared worlds. Let us next explore this path.

\section{Encountering Non-humans that Make Worlds}

Much nature conservation is about wildlife - where are the wildlife in the ethnographies then? Or the plants? And other non-humans? The ethnography of conservation has, in line with the disciplinary tradition of social anthropology, focused on humans' experiences and perspectives only. The growing movement of multi-species ethnography (Kirksey and Helmreich 2010; Ogden, Hall, and Tanita 2013; Kirksey 2014; Dooren, Kirksey, and Münster 2016), as well as the longer traditions of ethnobotany and human-animal studies, or anthrozoology (Mullin 2013), have impacted the anthropological literature on conservation's encounters remarkably little.

Tsing $(2005,173)$ thus finds in social science accounts of conservation a mirror image of conservation biology:

Social scientists extend the kind of simplification and neglect conservation biologists apply to humans to nonhumans. We rarely hear about the lives of plants and animals; we hear only how they enter human plans. We tap into literatures on symbols and meanings, on class and colonialism, on commodification and the penetration of capitalism. But these literatures do little to help us understand nature: its diversity, its power and constraints, or its multifaceted ways of entering human histories.

Thus, one way to wild the ethnography - and to show that nature is central to conservation's encounters - would be to treat animals, plants, other living beings, and the nonhuman world-making projects in all landscapes as significant actors. All organisms make worlds; their living activities are their own specific world-making 'projects' (Tsing 2015, 292). If we are to understand conservation as an encounter between disparate world-making projects, we thus need to learn about the specific ways how various animals, plants, and all other living beings, especially those targeted for conservation, make their worlds - and co-make our planet. This would also help us explore nature's values and conservationists' value-beliefs. For example, animals, plants, and other nature have 'agency' by 'interpellating' people into 'loving' them, feeling awe, and valuing them. The smells of the forest, waves of the sea, or sights of parenting by a mammal or bird all impact human subjects, including conservationists (Kiik 2019).

Thus, to understand conservation encounters more comprehensively, we need morethan-human ethnography of world-making encounters. Barua (2015) has similarly stated why conservation encounters are multi-species: 'Encounters forge "contact zones", where people across cultures, with different histories come together into composition, interact, and intertwine. But encounters are also between beings of biologically different origins, equally vital to such histories and world-making'. Thinking further, Aisher and Damodaran (2016) suggest analysing nature conservation's multi-species encounters and assemblages not on a global, but on the landscape scale, because 'encounters occur in places' (emphasis added). However, we need not only theoretical groundwork for including other-than-humans, but also the actual ethnography where multi-species 
worlds come to life. As Mathews $(2011,26)$ puts it, 'a study of social and environmental change without an active and intransigent nature is a drama stripped of its principal actors'.

Currently, most ethnographies of conservation encounter do not describe the lifeways of animals and nature in the studied landscapes. For example, Haenn (2005) does not write about jaguars beyond when one was captured. Lowe (2006) does not write about the monkeys through whom a park's founding was justified. And Kockelman's (2016) semiotic approaches to chicken and quetzal do not include those birds' actions upon the world, only human perceptions of and actions onto them. On the other hand, even though Jalais (2014) does not highlight tigers' life-worlds, her ethnography does elucidate how tigers and other animals act upon the human social world, notably by killing many people.

Among ethnographies of conservation, Ogden (2011) articulates uniquely why multispecies relations and natural processes matter. Ogden's poetic 'landscape ethnography' of a US marshland 'focuses on the world-making practices of poor rural whites ..., alligators, snakes, mangroves, and fire'. The marshland has its 'own logic and rules of engagement ..., encompassing the flow of nutrients through marshes, the lifeworlds of animals and plants, algae, and the like'. This landscape has a cosmopolitics of nature: the humans' and alligators' territorial practices interact; seasonal fluctuations of available water, heat, and fire disrupt linear time; 'creatures, nutrients, charged particles, and plant life' travel alongside hunters across the landscape; and global warming and sea level rise are 'the perfect example of a powerful socionatural process'. One reviewer, however, criticises that this ethnography still 'does little to show the ways in which the animals... (whether "gator, otter, raccoon or waterfowl") act in meaningful ways to influence [all the other actors]' (Malindine 2014). The reviewer suggests learning from the stories of native hunters who interact with the wildlife's agency.

Much inspiration for crafting a multi-species conservation ethnography can also be found in Hathaway's chapter on the agency of wild elephants (Hathaway 2013, Ch 5). Hathaway describes interactions with many 'actants, including organisms such as rice, corn, dogs, and oxen and material objects such as guns, electric fences, and dynamite'. He suggests that elephants helped put China's Yunnan province into transnational conservation networks - neither intentionally nor individually, but through 'cumulative agency'. That kind of animal agency spreads far:

Elephants' everyday acts - eating people's rice and corn, destroying houses, threatening human bodies - ... impact how humans organize themselves as well as how they literally shape landscapes and affect other species besides humans... The fact that elephants desire cultivated rice and corn more than wild bamboo in the forest is one critical way that their lives have been transformed in relationship to humans. In turn, the fact that elephants seek out farmers' fields has powerful effects on how farmers plant their fields, try to protect their crops, and interact with state officials. Regardless of elephants' intent, their continued presence in Yunnan is changing many people's lives, including how planners design and modify new roads, how nature reserve staff lobby to expand the size of reserves based on elephants' travels, and how scientists and elephant advocates carry out research and try to devise development projects to address human-elephant conflict. (157-158)

Some animals themselves labour for conservation. Münster (2016) portrays this in a protected forest where captive elephants and their human keepers have worked hard for 
decades to create and manage a forest, including by forcing wild and dangerous elephants away from farmers' paddies. The largely invisible and undercompensated work of these human-elephant teams belongs in 'a silent history of more-than-human environmental labour stretching back to colonial times'.

Beyond living beings, there are countless non-living things that people will encounter when they try understanding, gaining livelihood from, and managing nature. Mathews $(2011,25)$ highlights this when describing how an 'unruly' nature inserts itself into conservation's encounters:

Pine trees, roads, documents, and chainsaws are all stubbornly resistant material things and active participants in human projects. Loggers, farmers, foresters, and road builders come to know themselves in encounters with corn plants, marking hammers, documents, and wet roads. People bring these kinds of knowledge of self and the world to their encounters with the state [and its conservation projects].

Methodologically, multi-species ethnographies that relate to conserving nature have drawn both from life sciences and from environmental humanities and arts. Barua (2014), for example, engages the sciences of ethology and physiology to show how alcohol participates in human-elephant conflict. Tsing (2015) elevates the matsutake mushrooms' ecological niche of denuded forests into a symbol of hope for making multi-species worlds in the planet's many ruined landscapes. The 'extinction studies' literature, mentioned above, exemplifies how to portray the agency of nature and animals richly and experimentally through literary techniques.

Pursuing multi-species ethnography of conservation can also return us to ponder how to unite concern both for human social justice and for wildlife and other nature. Multi-species ethnography's goal may be stated as 'to push humans from center stage to study the lives and deaths of critters who abide with us in multi-species worlds' (Kirksey 2014, 4). Yet, how can one really push from centre stage the poorer countries' underclasses - the humankind's majority that has hardly ever been on the global 'centre stage'? Futurist strands of multispecies writing, which often explore how the emerging (micro-)biotechnology may impact rich democratic societies, offer us critical and progressive imaginaries for worlds yet-to-be. Yet, those visions tend to neglect some of humankind's most widespread and popular world-making projects, such as nationalism, religious revival, and authoritarianism, seemingly viewing them as bygone or less inspiring. Multi-species and wilded ethnographies of conservation can perhaps contribute to the literature on multi-species utopianism by centring such thorny disconnects.

Finally, addressing such political and ethical cleavages, conservation ethnography might ask, can world-making by animals, say whales or hornbills, be included in the notion of cosmic, cross-species politics, or diplomacy? Who speaks for whales, hornbills, microbes? Is it, among others, the natural sciences?

\section{Weaving Natural Sciences into Ethnography}

Socio-anthropological literature has shown why natural sciences do not offer the sole, unavoidable, or necessarily most pertinent way to understand nature as a (human) value and as an actor in (more-than-)human worlds. Many a social anthropologist has protested against the idea that natural sciences are a privileged representative of animals and 
nature, or provider of insight into animal worlds. Blaser (2016), for instance, has criticised multi-species ethnography for tending 'to rely heavily on the natural sciences as spokespersons for the nonhumans admitted into politics'. Ethnographies of conservation have been particularly sceptical in situations where transnational conservationists clash with, dispossess, or attempt to govern native societies by appealing to scientific authority, sometimes poorly proven and more rhetorical than substantive.

Indeed, the primary way that conservation ethnographies have engaged natural sciencebased arguments has, in my reading, been to question certain popular scientistic narratives, defend native people, and point out the lack of science in conservation practice. At various fieldsites worldwide, ethnographies of conservation have suggested that newly arrived conservationists lack a scientific research basis, first, for claiming that local wildlife are disappearing, second, for assuming that local villagers should be blamed, and third, for requesting and delineating new protected areas (MacDonald 2004; Haenn 2005; Lowe 2006; West 2006; Vivanco 2007; Jalais 2014). For example, Ogden (2011) acknowledges, yet simultaneously questions, that hunting has denuded a wildlife population at her fieldsite: 'Although alligator hunting seems to have posed a serious threat to alligator populations in Florida, few scientific studies support this assertion. However, the anecdotal evidence that hunting threatened the viability of alligators in the Everglades is hard to dismiss'. Keller (2015) rejects the 'canonical' narrative that early human settlers destroyed Madagascar's forest and species - by referring to scholarship that is contested and more nuanced. In a way, these examples of challenging conservationists on their lack of scientific basis are a way how ethnographers have taken sciences and conservation more seriously than conservationists sometimes do.

Some ethnographies of conservation have shown paths toward engaging natural sciences further - by emphasising that natural scientists and native peoples, including native animists, share common intellectual grounds. As Rival (2014) puts it, scientists and indigenous experts can talk about the specifics of nature because they share mutually compatible 'ecological reasoning'. Cepek (2012), too, articulates a 'pragmatist' approach to reasoning that is shared by both indigenous people and scientists. Walley $(2010,214)$ mentions that albeit many conservation professionals at her fieldsite 'assumed rigid boundaries between scientific and popular knowledge', when given the chance, the Western professionals and native residents did converse and learn mutually - for example, about how fruit bats pollinate baobab trees or how to differentiate types of termites. And notably, Lowe (2006, xi-xii) focuses on people's thought and 'reason' to co-frame analytically the urbanite conservationists and the native people - both groups are 'struggling to solve particular problems of nature and nation' within the given political situation's 'degrees of freedom and constraint'. Both scientists and native experts try fixing their respective 'empirical gaps' about ecology - albeit scientists work in vaster scales and have better resources for improving their claims' accuracy and comprehensiveness (Macintyre and Foale 2013). Certainly, when an ethnographer tries to better understand local nature, both native expertise and transnational natural science offer valuable insights.

Yet, ethnographies of conservation encounter rarely cite or engage natural-scientific publications or research results, especially for purposes other than to criticise conservationists or defend native people against accusations. This neglect of biophysical sciences largely reflects a trend in political ecology - the interdisciplinary field wherein many, but not all, conservation anthropologists write. Thus, those anthropologists who come 
from more ecologically inclined traditions, such as human ecology, have criticised political-ecology research for over-prioritising political-economic systems (Vayda and Walters 1999) and asked instead: 'where is the ecology?' (Walker 2005). Indeed, while conservationists routinely undermine their own projects by failing to consult contemporary ethnographic literature about their project area (MacDonald 2003; West 2006, 2016b), social anthropologists of conservation can likewise benefit from crossing disciplinary and epistemic boundaries in the opposite direction.

The ethnography of environmental conservation could keep its critical and relativist instincts, yet benefit from engaging more with the insights which natural sciences offer into the world-makings of animals, plants, and many others - and into the existential crises that these worlds now face. In this vain, Swanson (2017) suggests social anthropologists approach life sciences as we already approach history archives - aware of their power relations and non-neutrality, but nonetheless often using their data pragmatically as 'good enough'. Moreover, Mathews (2011, 25-28) suggests that we can use natural science research to actually transcend 'a naïve positivism'. Namely, to show nature's agency both in and upon his ethnography of conservation, Mathews studies the constraints of ecology and climate as ways that nature offers 'resistances' 'to both my own analysis and to the projects of foresters and farmers' - indeed, to all knowing. Thus, the challenge could be less about accepting natural-scientific data and more about how to integrate it into ethnographic thinking and writing.

Consulting natural sciences could help us when trying to address specific questions about our fieldsites. Some such questions may be: What is the actual situation of the region's populations of certain life species? What kind of lives do these beings live; what kind of worlds do they make? How exactly is farming, mining, or dam construction impacting landscapes, rivers, and soils? How do thereby the life-worlds of plants, animals, and people shift? What do GIS maps say about changes in forest cover? And so forth. Each of these questions would contribute to wilding the ethnography of conservation by paying deeper attention to natural, other-than-human worlds and their unfolding crises. Each of these questions would also demand collaboration with specialists, extensive research, and interdisciplinary conversation.

Methodologically, one collaborative strategy for weaving natural sciences into ethnographic writing, particularly on multi-species world-makings, has been demonstrated by Tsing $(2013,2015)$. She has suggested turning to old-school natural history as a genre that is particularly compatible with ethnography: both value non-quantitative detailed description. Natural history, field ecology, and ethnography as fields also share instincts of prioritising fieldwork and observation (Rival 2014), or what Tsing calls 'noticing'. In her ethnography then, Tsing mixes human and environmental histories in rich storytelling about mushroom world-makings. This approach also resembles Ogden's (2011) ethnography which, too, embedded natural history into its story-telling.

However, practically speaking, an ethnographer not trained in the natural sciences, such as me, will unlikely turn into an expert natural historian and will thus rely on collaboration with specialists. Thus, Tsing relies on natural scientist colleagues whom she presents as characters in her ethnography. She learned from and re-told their discoveries and descriptions, weaving these into her ethnography to talk about how the mushrooms, trees, and others make worlds. Indeed, having Japan as her fieldsite gave Tsing uniquely beneficial access to descriptive scientists because much of Japanese academia, compared 
to other countries, continues to value description over scalable theory and models. Nonetheless, anthropologists can pursue natural history even when there are no descriptive natural scientists currently working in their studied region. For example, there may be descriptive accounts by colonial era European administrators and botanists, as well as by the country's later national scientists or contemporary conservationists. Moreover, we can learn much by simply asking the biologists and conservationists. For example, my own fieldsite's conservation professionals taught me how a native society's popular explanations of why wild animals disappeared or a microclimate changed compare and clash with natural-scientific understandings.

We can learn much about a place's ecology by doing classic participant observation whether with native experts and residents or with conservation actors and scientists. Native people's farming, gardening, hunting, fishing, gathering, and tree-cutting, as well as the conservation actors' wildlife surveying and park warding, and other such field activities, are all important entryways for learning through participant observation and for pursuing rich natural-historic and multi-species data. These activities provide opportunities to trek across and stay in the conservation-targeted landscapes, encounter common wildlife and plants, and to learn from people's ethnobiological and experiential knowledge. Attending to the ways that human sociality interrelates with (wild and domestic) animals, plants, weather, minerals, and soil helps later create an ethnographic portrait of biodiversity conservation that incorporates non-human agency. In later writing, such fieldwork-based nature description can be combined with natural-scientific research data about specific life-forms and ecosystems, as well as ethnographic data about more-than-human worlds. The goal would be to embed other-than-humans into the eventual ethnography in diverse ways that show their 'agency' in shaping the conservation encounter.

To understand this agency and world-making, Swanson $(2017,86)$ urges ethnographers to move beyond even natural history and collaborate with life-scientists in laboratory research. She notes that natural history 'still looks a lot like the "deep hanging out" that is familiar and comfortable to anthropologists'. Consequently, 'expanding ethnography through natural history observations does not help us methodologically with things we cannot directly and personally see', such as 'microbes, ocean currents, long-term evolutionary processes', and, in Swanson's research, salmons' migrations, inter-species relations, and life-worlds. Integrating laboratory science data into the ethnography of conservation would help explore animals and other living beings beyond their intimate encounters with people. It would thus also help 'get the size of humans right' - inside vastly broader multi-species networks where 'human practices play a role, but not necessarily an always dominant one'.

Simultaneously, both the scientific literature and conservation research activities are suitable for a critical, Science and Technology Studies form of analysis. Ethnographers have investigated how the science-making and scientific facts about the region's ecology are established for conservation-political agendas and in accordance with natural scientists' ontological assumptions (for example, Lowe 2006). Ethnography can also explore conservation's field-working and paper-writing as world-making practices within a Global South-and-North transnational cooperation, contest, and negotiation (Kiik 2019). Reading the natural-scientific literature and participating in conservation research can help ethnographers explore how nature conservationists decide where and how to proceed. 
Overall then, engaging natural science data and ecological knowledge in these or other ways can help expand the ambition of the ethnographic representation of conservation's encounters - and better show that nature is a key participant in those encounters. Such interdisciplinary engagements become particularly salient as social anthropology increasingly treats the world beyond the explicitly human as its business - and tackles the global environmental crises of the Anthropocene as its research topic. The ethnography of conservation encounters would also do well to further embrace the ecological and holistic tradition within anthropology, from ethnobotany to human ecology. A wilder ethnography of conservation can, among else, contribute to integrating disciplinary knowledge at the growing interface between social anthropology and conservation science.

\section{Conclusion}

Ethnographies of conservation practice have often analysed how states' and NGOs' environmental projects clash with, misunderstand, and maltreat native societies. However, these writings have paid less attention to the nature - the plants, animals, this planet's non-human worlds - that both participates in and motivates the studied encounters. Nature and non-humans first participate by inspiring conservation professionals to intervene into diverse places and societies. They also participate by conditioning and entering the consequent encounters, and acting in self-willed ways. Therefore, this paper explored the existing literature to seek paths toward 'wild-ing' the ethnography of conservation, particularly by writing more-than-human values, actors, and data into our ethnographies. The discussion was structured through the following three themes.

First, ethnography of conservation practice could engage deeper with the worldwide ecological crises and the environmentalist valuing of nature - not least because these crises and values originally motivate the studied practices and encounters. Currently, many ethnographies of conservation encounter neither explore local or global ecological crises as worthwhile topics of explicit study nor express concern for nature, landscapes, or wildlife as inherently valuable. However, some ethnographic and humanities literature offers paths toward exploring the ethical hierarchies, anxieties, and choices of caring for nature's survival.

Second, conservation is all about wildlife and other nature - where are the animals, plants, and other life-forms among the ethnographic characters then? Most ethnographies of conservation rarely describe the lifeways of wildlife in the protected or unprotected landscapes under study. Yet, some existing ethnographies have gained in accuracy and fullness by treating the animals, plants, other living beings, and ecological dynamics as significant co-makers of our worlds. A wilder ethnography embeds other-than-humans and natural worlds into its story-telling - to show nature's 'agency' in shaping all conservation encounters.

Finally, most ethnographies of conservation practice rarely cite or engage natural-scientific publications or research results, unless for criticising conservationists' misrepresentations or defending native people against accusations. Yet, the representation of conservation encounters could benefit from involving natural-scientific understandings to better describe places, conservation practices, and the world-makings of animals, plants, and other life-forms, as well as the planet's environmental crises and prospects. Ethnographers can partially rely on classic participant observation, question-asking, and 
story-telling - as with indigenous experts, so too with the conservation practitioners and scientists. There is also a long tradition of ecological and holistic anthropology to draw on.

Altogether, this paper pursued elevating nature's value and agency as two explicit principles in a wild ethnography of biodiversity conservation. It did not argue that studying native experiences of conservation interventions, often unjust and hidden, is any less important. Instead, a wilder ethnography of conservation could perhaps meditate on how to sense and represent at once both nature's worldwide demise and the suffering of deprived people. Such reflection can, too, connect social anthropology and conservation science.

The ensuing anthropological challenges may be about specificity and sensitivity. For example, having established that other-than-human agency matters - from rocks to elephants to fungi - the next challenge may be to specify that animals, people, non-living things, and so forth have different kinds of agency, relations, and world-making. Ethnography needs to show how a rhino's agency differs from an anthropologist's agency or a hornbill's agency - and how these further differ from the 'agency' of a stone or an ocean. Bringing into our ethnographies specific animals and natural actors - while learning from natural-scientific research about those actors' worlds and about how their worlds mutually relate in ecosystems and across the planet - helps us refrain from ontological 'over-flattening', that is, from making all actors look the same. It also helps us specify how and why people, including ethnographers and conservationists, value different actors and systems of nature at different degrees. To reflect on nature's value, we can also learn from environmental humanities literature that mourns for the planet's vanishing natural worlds. Altogether, more-than-human ethnography, natural-scientific data, and ethical meditation can be joined to better represent how nature - its values, worldmaking, and disappearing - shapes conservation practice across the world.

\section{Acknowledgements}

I am grateful for the guidance by Cathel Hutchison, Coll Hutchison, Marshall Kramer, Sahil Nijhawan, Laura Rival, and two anonymous reviewers. All mistakes are mine.

\section{Disclosure Statement}

No potential conflict of interest was reported by the authors.

\section{ORCID}

Laur Kiik (i) http://orcid.org/0000-0003-2552-8971

\section{References}

Agrawal, A. 2005. Environmentality: Technologies of Government and the Making of Subjects. Durham, NC: Duke University Press.

Aisher, A., and V. Damodaran. 2016. "Introduction: Human-Nature Interactions Through a Multispecies Lens." Conservation and Society 14 (4): 293. doi:10.4103/0972-4923.197612.

Anderson, D. G., and E. K. Berglund. 2003. Ethnographies of Conservation: Environmentalism and the Distribution of Privilege. New York: Berghahn Books. 
Barua, M. 2014. "Volatile Ecologies: Towards a Material Politics of Human - Animal Relations." Environment and Planning A 46 (6): 1462-1478. doi:10.1068/a46138.

Barua, M. 2015. "Encounter.” Environmental Humanities 7 (1): 265-270.

Blaser, M. 2016. “Is Another Cosmopolitics Possible?” Cultural Anthropology 31 (4): 545-570.

Brockington, D., R. Duffy, and J. Igoe. 2008. Nature Unbound: Conservation, Capitalism and the Future of Protected Areas. London: Earthscan.

Brosius, J. P., and S. L. Hitchner. 2010. "Cultural Diversity and Conservation.” International Social Science Journal 61 (199): 141-168. doi:10.1111/j.1468-2451.2010.01753.x.

Bryant, R. L. 2002. "Non-Governmental Organizations and Governmentality: 'Consuming' Biodiversity and Indigenous People in the Philippines." Political Studies 50 (2): 268-292. doi:10.1111/1467-9248.00370.

Campbell, B. 2009. "Beyond Cultural Models of the Environment." In Culture and the Environment in the Himalaya, edited by A. Guneratne, 186-203. London: Routledge.

Campbell, B. 2013. Living Between Juniper and Palm: Nature, Culture, and Power in the Himalayas. Oxford: Oxford University Press.

Cepek, M. L. 2012. A Future for Amazonia: Randy Borman and Cofán Environmental Politics. Austin, TX: University of Texas Press.

Dooren, T. van. 2014. Flight Ways: Life and Loss at the Edge of Extinction. New York: Columbia University Press.

Dooren, T. van, E. Kirksey, and U. Münster. 2016. "Multispecies Studies Cultivating Arts of Attentiveness." Environmental Humanities 8 (1): 1-23.

Fairhead, J., and M. Leach. 1996. Misreading the African Landscape: Society and Ecology in a ForestSavanna Mosaic. Cambridge: Cambridge University Press.

Fairhead, J., M. Leach, and I. Scoones. 2012. "Green Grabbing: A New Appropriation of Nature." Journal of Peasant Studies 39 (2): 237-261. doi:10.1080/03066150.2012.671770.

Haenn, N. 2005. Fields of Power, Forests of Discontent: Culture, Conservation, and the State in Mexico. Tucson, AZ: University of Arizona Press.

Haraway, D. J. 2016. Staying with the Trouble: Making Kin in the Chthulucene. Durham: Duke University Press.

Hathaway, M. J. 2013. Environmental Winds: Making the Global in Southwest China. Berkeley: University of California Press.

Heatherington, T. 2010. Wild Sardinia: Indigeneity and the Global Dreamtimes of Environmentalism. Seattle: University of Washington Press.

Heise, U. K. 2016. Imagining Extinction: The Cultural Meanings of Endangered Species. Chicago: University of Chicago Press.

Jalais, A. 2014. Forest of Tigers: People, Politics and Environment in the Sundarbans. London: Routledge.

Kagan, S. 2016. "What's Wrong with Speciesism? (Society of Applied Philosophy Annual Lecture 2015)." Journal of Applied Philosophy 33 (1): 1-21. doi:10.1111/japp.12164.

Keller, E. 2015. Beyond the Lens of Conservation: Malagasy and Swiss Imaginations of One Another. New York: Berghahn Books.

Kiik, L. 2016. "Conspiracy, God's Plan and National Emergency: Kachin Popular Analyses of the Ceasefire Era and its Resource Grabs." In War and Peace in the Borderlands of Myanmar: The Kachin Ceasefire, 1994-2011, edited by M. Sadan, 205-235. Copenhagen: NIAS Press.

Kiik, L. 2019. "Conservationland: Toward the Anthropology of Professionals in Global Nature Conservation." Critique of Anthropology 39 (3).

Kirksey, E. 2014. The Multispecies Salon. Durham, NC: Duke University Press.

Kirksey, E., and S. Helmreich. 2010. "The Emergence of Multispecies Ethnography." Cultural Anthropology 25 (4): 545-576. doi:10.1111/j.1548-1360.2010.01069.x.

Kockelman, P. 2016. The Chicken and the Quetzal: Incommensurate Ontologies and Portable Values in Guatemala's Cloud Forest. Durham, NC: Duke University Press.

Kopnina, H. 2016. "Nobody Likes Dichotomies (But Sometimes You Need Them)." Anthropological Forum 26 (4): 415-429. doi:10.1080/00664677.2016.1243515. 
Lowe, C. 2006. Wild Profusion: Biodiversity Conservation in an Indonesian Archipelago. Princeton, NJ: Princeton University Press.

MacDonald, I. K. 2003. "Political Ecology and the Demand for Organizational Ethnography." https://tspace.library.utoronto.ca/handle/1807/9920.

MacDonald, K. 2004. "Developing 'Nature': Global Ecology and the Politics of Conservation in Northern Pakistan." In Confronting Environments: Local Environmental Understanding in a Globalising World, edited by J. G. Carrier, 71-96. Walnut Creek, CA: AltaMira Press.

Macintyre, M., and S. Foale. 2013. "Science, Traditional Ecological Knowledge, and Anthropology: Managing the Impacts of Mining in Papua New Guinea." Collaborative Anthropologies 6 (1): 399-418.

Malindine, J. 2014. "Review of: Swamplife: People, Gators, and Mangroves Entangled in the Everglades, Laura A. Ogden. 2011.” Culture, Agriculture, Food and Environment 36 (1): 6162. doi:10.1111/cuag.12031.

Mathews, A. S. 2011. Instituting Nature: Authority, Expertise, and Power in Mexican Forests. Cambridge, MA: MIT Press.

Milton, K. 2002. Loving Nature: Towards an Ecology of Emotion. London: Routledge.

Mullin, M. 2013. "Anthrozoology." Oxford Bibliographies in Anthropology. http://www. oxfordbibliographies.com/display/id/obo-9780199766567-0072.

Münster, U. 2016. "Working for the Forest: The Ambivalent Intimacies of Human-Elephant Collaboration in South Indian Wildlife Conservation." Ethnos 81 (3): 425-447. doi:10.1080/ 00141844.2014.969292.

Novellino, D. 2003. "Contrasting Landscapes, Conflicting Ontologies: Assessing Environmental Conservation on Palawan Island (the Philippines)." In Ethnographies of Conservation: Environmentalism and the Distribution of Privilege, edited by D. G. Anderson and E. Berglund, 171-188. New York: Berghahn Books.

Nustad, K. G. 2015. Creating Africas: Struggles Over Nature, Conservation and Land. Oxford: Oxford University Press.

Ogden, L. 2011. Swamplife: People, Gators, and Mangroves Entangled in the Everglades. Minneapolis: University of Minnesota Press.

Ogden, L. A., B. Hall, and K. Tanita. 2013. "Animals, Plants, People, and Things: A Review of Multispecies Ethnography." Environment and Society 4 (1): 5-24.

Ortner, S. B. 2016. "Dark Anthropology and Its Others: Theory Since the Eighties." HAU: Journal of Ethnographic Theory 6 (1): 47-73. doi:10.14318/hau6.1.004.

Peluso, N. L. 1993. "Coercing Conservation? The Politics of State Resource Control." Global Environmental Change 3 (2): 199-217.

Raffles, H. 2014. In Amazonia: A Natural History. Princeton, NJ: Princeton University Press.

Redford, K. H. 2011. “Misreading the Conservation Landscape.” Oryx 45 (3): 324-330. doi:10.1017/ S0030605311000019.

Rival, L. 2014. "Encountering Nature Through Fieldwork: Expert Knowledge, Modes of Reasoning, and Local Creativity." Journal of the Royal Anthropological Institute 20 (2): 218-236. doi:10.1111/ 1467-9655.12101.

Robbins, J. 2013. "Beyond the Suffering Subject: Toward an Anthropology of the Good." Journal of the Royal Anthropological Institute 19 (3): 447-462. doi:10.1111/1467-9655.12044.

Rose, D. B. 2011. Wild Dog Dreaming: Love and Extinction. Charlottesville: University of Virginia Press.

Rose, D. B., and T. Van Dooren. 2011. "Unloved Others: Death of the Disregarded in the Time of Extinctions." Australian Humanities Review (special issue) 50: 1-178.

Rose, D. B., T. van Dooren, and M. Chrulew. 2017. Extinction Studies: Stories of Time, Death, and Generations. New York: Columbia University Press.

Sodikoff, G. M. 2012. The Anthropology of Extinction: Essays on Culture and Species Death. Bloomington: Indiana University Press.

Swanson, H. A. 2017. "Methods for Multispecies Anthropology: Thinking with Salmon Otoliths and Scales." Social Analysis 61 (2): 81-99. doi:10.3167/sa.2017.610206. 
Theodossopoulos, D. 2003. Troubles with Turtles: Cultural Understandings of the Environment on a Greek Island. New York: Berghahn Books.

Toussaint, Y. 2005. "Debating Biodiversity: Threatened Species Conservation and Scientific Values.” The Australian Journal of Anthropology 16 (3): 382-393. doi:10.1111/j.1835-9310. 2005.tb00318.x.

Tsing, A. L. 2005. Friction: An Ethnography of Global Connection. Princeton, NJ: Princeton University Press.

Tsing, A. 2013. “More Than Human Sociality: A Call for Critical Description.” In Anthropology and Nature, edited by K. Hastrup, 27-42. London: Routledge.

Tsing, A. L. 2015. The Mushroom at the End of the World: On the Possibility of Life in Capitalist Ruins. Princeton, NJ: Princeton University Press.

Vayda, A. P., and B. B. Walters. 1999. “Against Political Ecology.” Human Ecology 27 (1): 167-179. doi:10.1023/A:1018713502547.

Vivanco, L. A. 2007. Green Encounters: Shaping and Contesting Environmentalism in Rural Costa Rica. Vol. 3. New York: Berghahn Books.

Walker, P. A. 2005. "Political Ecology: Where is the Ecology." Progress in Human Geography 29 (1): 73-82. doi:10.1191/0309132505ph530pr.

Walley, C. J. 2010. Rough Waters: Nature and Development in an East African Marine Park. Princeton, NJ: Princeton University Press.

West, P. 2006. Conservation is Our Government Now: The Politics of Ecology in Papua New Guinea. Durham, NC: Duke University Press.

West, P. 2016a. "An Anthropology for 'the Assemblage of the Now'.” Anthropological Forum 26 (4): 438-445.

West, P. 2016b. Dispossession and the Environment: Rhetoric and Inequality in Papua New Guinea. New York: Columbia University Press.

West, P., J. Igoe, and D. Brockington. 2006. "Parks and Peoples: The Social Impact of Protected Areas." Annual Reviews in Anthropology 35: 251-277. doi:10.1146/annurev.anthro.35.081705. 123308. 